\title{
Efficiency of Informatics Tools to Project Development in Project-Based Learning Activities for Collaborative Engineering
}

\author{
Samuel Dereste dos Santos ${ }^{1,2}$, Oduvaldo Vendrametto ${ }^{1}$, \\ Miguel León González ${ }^{2}$, and Mário Mollo Neto ${ }^{1}$ \\ ${ }^{1}$ Paulista University-UNIP, Dr. Bacelar St. 1212, Sao Paulo, Brazil \\ samuel_dereste@yahoo.com.br, \\ \{oduvaldov, miguel.leon\} @uol.com.br, \\ mariomollo@gmail.com \\ ${ }^{2}$ Cruzeiro do Sul University-UNICSUL, Dr. Ussiel Cirillo Ave. 225, Sao Paulo, Brazil
}

\begin{abstract}
Informatics tools are very important for project development in the civil engineering area. CAD - Computer Aided Design - tools are freely used in different project routines, but BIM - Building Information Modeling are gaining space to allow the development of objects with a larger number of parameters and permit a collaborative engineering. Besides, the PBL - Project Based Learning - tools can be effective for teaching, allowing students to combine prior knowledge and aggregates skills in a collaborative model in engineering area. The objective of the paper is analyzing software applications in a PBL activity focusing the results of CAD and BIM tools utilization in project development. The methodology adopted was a technical review and a case study of $21 \mathrm{PBL}$ projects developed by students of a civil engineering graduation course. The results shows that PBL is a good strategy for project development, and BIM tools are more efficient when compared with CAD tools.
\end{abstract}

Keywords: Project Based Learning, Building Information Modeling, Computer Aided Design, collaborative engineering.

\section{Introduction}

The use of computer tools in an undergraduate course in civil engineering aims to develop projects in software available in the market, establishing a bridge between what is taught in the university with is developed in the professional life. Specifically about tools for project developing, in a first moment as a direct replacement of the clipboard and handmade draws, the CAD tools - computer aided design - meant a revolution in the design process, making it more productive and enabling the exchange and use of information quite effectively, covering various technology areas such as aeronautics, mechanics and construction.

Besides CAD tools, the BIM - Building Information Modeling - was developed, specifically for the project of buildings, and have another concept. The CAD technology is based on vector information and BIM in parametric objects. It allows to the 
designer to define a series of objects that make the process more interactive and rich, allowing it to resolve several problems prior to construction. Furthermore, its architecture allows the same file under different disciplines, such as facilities, structure, masonry, foundations, etc. The production of the project information is simultaneously and significantly decreases the work for project's compatibilization.

The formation process of a civil engineer consists of a basic curriculum, like Physics, Chemistry and Calculus, to give the basic reasoning and elementary tools for the continuity of the course. In the specific curriculum, the objective is to give the knowledge necessary for the professional life. One challenge in this context is aligning with the new challenges and consequences of globalization, like a humanist, critical and reflexive formation, enabling the development new technologies and contributions to attend the society demands.

One strategic tool that can be applied to aggregate competences in graduation courses are Project Based Learning - PBL - activities. This methodology focuses in project development and has the objective of simulating the real life. In the PBL, the center of the learning process is the student, whose role is to find information and aggregate knowledge, which is a paradigm shift.

The objective is to analyze software application in a PBL activity - inside a civil engineering graduation course - focusing the results of CAD and BIM tools utilization. The methodology was a technical review about informatics tools and Project Based Learning, besides a case study of 20 project developed by students in a PBL activity, whose results was ranged to be analyzed in the context.

\section{Technical Review}

\subsection{Informatics Tools Used in the Development of Projects}

To define the most common tools used in the development of projects in civil construction, it is necessary to study the importance of CAD and BIM tools in the context.

\subsubsection{CAD Tools}

The first applications of computers to assist the stages of engineering began in 1950, when the Massachusetts Institute of Technology - MIT - started the discussion about CAD - Computer Aided Design - technology. The CAD systems of this generation were limited to the description of two-dimensional vector geometrics entities for creating and manipulating drawings. The CAD tools denoted the transfer of manual draws to an electronic platform, with the advantages like electronically sent and received drawings, better management of the information, best currency in size and fast drawing modification.

At the end of the 90s, with the development of the Windows Operating System, there was a migration of the companies for Windows tools. This fact reduced the cost of hardware / software and the need for highly skilled users, popularizing the tool. [1]. The DWG interface is one of the most popular interface in civil construction planning offices, but the difficulties with files communication made the development of 
another software and formats to become the project process more efficient. One of these interfaces are BIM - Building Information Modeling - tools.

\subsubsection{BIM Tools}

The first concepts of BIM dates to the first attempts of data optimization at CAD platforms. This is a three-dimensional model enriched by additional intelligence (parameters). The basis of this technology consists of the graphical information, which includes the geometric model construction, its physical characteristic, properties, names and functional peculiarities of its components [2].

BIM systems are adequate to support the simulation of a construction project in a virtual environment, with the advantage of using software to perform several steps of the construction process, allowing it to make the necessary adjustments. The assembly instructions can be associated with BIM components, so the visual context of the specific location on the 3D (three dimension) model can assist with the communication of instructions [1].

The BIM tools involves information modeling surrounding the production of a building by a digital model that integrates all the interfaces, covering the entire life cycle of the building, which starts in the project, involves the implementation, use, rehabilitation and demolition [3].

\subsection{Project Based Learning - PBL}

Project Based Learning - PBL - is defined as a competence-based education that integrates knowledge, skills and values. The models integrating project-based learning have their scientific basis in generating learning processes in which students are not passive recipients of knowledge. Following the trends in psychology of knowledge, project-based learning is grounded in the belief that humans construct new knowledge over a base of what we already know and of what we have experienced, which we make available through active participation and interaction with others [4].

The development of the PBL was originated in 1900, when John Dewey (18591952) presented the "learning by doing", valuing the capacity of students by thinking relative knowledge to solve real problems in projects, developing the emotional, intellectual and physical aspects. [5]

The PBL has been a major focus of discussion, as not only an active learning approach, but also how to develop alternative curriculum and adopting innovative practices in engineering education. Requires a teacher to reflect on the teaching activity and change their traditional stance of content specialist for coach learning, and that students assume greater responsibility of their own learning, with the understanding that the knowledge gained from your personal effort lasts longer than that obtained only by third-party information $[4,5]$.

The main features of this methodology are that the student is the center of the process, the work is developed in tutorial groups, it is characterized by being an active, cooperative, integrated and interdisciplinary process oriented student learning. For a good learning process in this methodology, is necessary to be aware of what the student knows and what he needs to learn and motivate the search for relevant 
information, stimulate the student's ability to learn to learn to work in teams, to hear other opinions, inducing him to take an active and responsible role for their learning and help students achieve the project objectives, which are: learn how to make an analytical and thorough examination of a problem, identify learning objectives, seek relevant information and learn to work in groups [4,5].

The learning projects favor the relationship of various contents making it easier for students to build their knowledge with the integration of different disciplinary knowledge in an interdisciplinary philosophy, seeking to pursue a meaningful learning. A study case about this methodology will be studied in the sequence.

\section{Case Study}

The case study is about an exercise developed by 21 groups in a civil engineering graduation course on $6^{\text {th }}$ semester. The conceptual bases for development were a PBL methodology in the development of a Residence and a Residential Building. Into this moment of the course, the students had disciplines about Topography, Construction Technology, Construction Materials, Technical Drawings and Architecture and Urbanism. In the last two, they studied CAD and BIM tools specifically.

To the development of the activities, there was proposed a scope, with these characteristics (Table 1).

Table 1. Scope of the activity

\begin{tabular}{|c|c|c|c|}
\hline \multicolumn{2}{|r|}{ Residence } & \multicolumn{2}{|c|}{ Residential Building } \\
\hline Building Sit & $10 \times 25$ meters & Building Sit & $50 \times 25$ meters \\
\hline $1^{\text {st }}$ floor & $\begin{array}{l}\text {-Living Room } \\
\text {-Lavabo } \\
\text {-Dining Room } \\
\text {-Kitchen } \\
\text {-Laundry } \\
\text {-Maid Room } \\
\text {-Maid Bathroom }\end{array}$ & $\begin{array}{l}\text { Common } \\
\text { area }\end{array}$ & $\begin{array}{l}\text {-Entrance / Lobby } \\
\text {-Hall } \\
\text {-Elevators / Escalators } \\
\text {-Party's Room } \\
\text {-Technical Room } \\
\text {-Collective Bathroom } \\
\text {-Pool } \\
\text {-Changing Room }\end{array}$ \\
\hline $2^{\text {nd }}$ Floor & $\begin{array}{l}\text {-TV room } \\
-2 \text { dormitory } \\
-1 \text { suite } \\
\text {-Collective Bathroom }\end{array}$ & Apartment & $\begin{array}{l}\text {-2 dormitory } \\
\text {-Living Room } \\
\text {-Kitchen } \\
\text {-Laundry } \\
\text {-Common Area }\end{array}$ \\
\hline $\begin{array}{l}\text { Technical } \\
\text { Area }\end{array}$ & Roof & $\begin{array}{l}\text { Technical } \\
\text { Area }\end{array}$ & Roof \\
\hline
\end{tabular}

\subsection{Work Groups and Orientation}

These activities were supervised and oriented by 3 professors of design and project area. The groups were divided in 4 or 5 students, who have a scale of orientation with the professors. 


\subsection{Software Adoption}

The students had, prior this activity, the disciplines of Technical Drawing and Architecture and Urbanism whose objective was introduce and practice CAD and BIM tools. The groups should choose between CAD or BIM tools by themselves to develop the activities. The professors would give support in both cases.

\subsection{Activity Development}

To develop the activities, 6 groups adopted BIM technologies, and 15 adopted CAD technologies. The groups, based on the scope, started the activities. Every group had weekly an orientation of 1 hour during 12 weeks. The tutors gave support of what was being developed and the prosecution. On the 13rd and 14rd week, they presented the projects to expose the results.

\subsection{Activity Results}

Each group presented the work to the professors, defending and discussing their ideas. Fig. 1 and Fig. 2 are examples of some works that were developed. All teams developed the proposed activities.

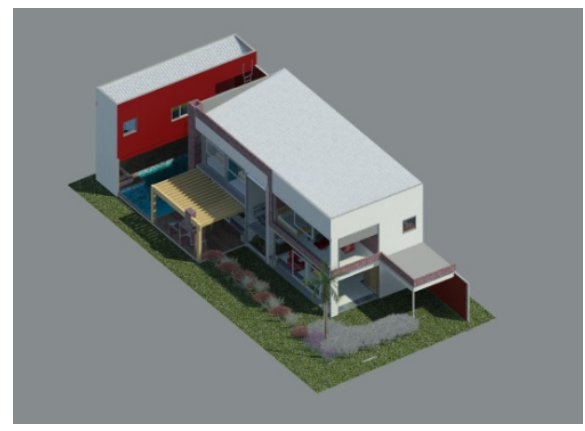

Fig. 1. Perspective

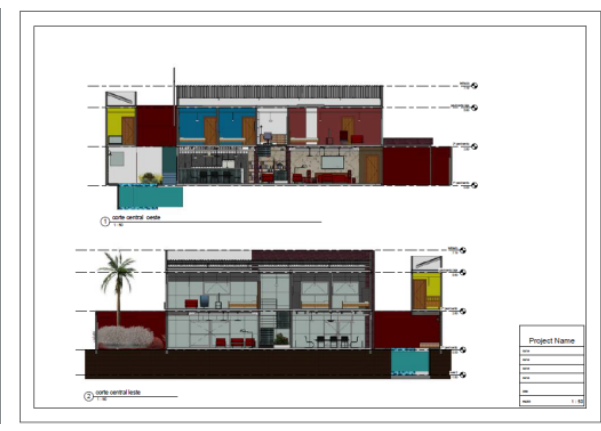

Fig. 2. Humanized Sections

The PBL model permitted to some students to learn some topics and change knowledge between colleagues, becoming the process very rich. Both tools permitted the analysis of all project instances (structure, masonry, electricity and hydraulics) with a good precision. Besides, the teams who adopted BIM solutions had more efficient projects representation than the teams that used CAD tools, what could inflict that the software could interfere in the process of project development. To investigate this fact, there was made, by the professors of the activity, a criteria analysis to understand this fact. 


\subsection{Software Analysis Criteria}

To establish a criterion, all the results were scored on a Likert Scale from 1 to 5, being 1 the worst quality and 5 the best quality. There was calculated a Standard Deviation (\%) for each product. It was analyzed the Graphic Representation - technical details of the execution of technical drawings norm in the construction area; Humanized Presentation - humanization of drawings for submission of the initial idea to the client, which is very important in professional life; Notations - sizes of text, dimensions, directions and projections for the proper understanding of technical drawing.

\subsection{Results of Software Analysis Criteria}

The result of the analysis of each project was rated in Table 2, with the respective evaluation of Graphic Representation, Humanized Presentation and Notation for BIM Teams and CAD Teams.

Table 2. Score Evaluation of the Products developed by groups

\begin{tabular}{|c|c|c|c|c|c|}
\hline & & \multirow{2}{*}{\multicolumn{2}{|c|}{$\begin{array}{c}\text { Number of Groups }=6 \\
\text { BIM Teams }\end{array}$}} & \multirow{2}{*}{\multicolumn{2}{|c|}{$\frac{\text { Number of Groups }=15}{\text { CAD Teams }}$}} \\
\hline & & & & & \\
\hline & & Plans & $\begin{array}{l}\text { Sections and } \\
\text { Facades }\end{array}$ & Plans & $\begin{array}{c}\text { Sections and } \\
\text { Facades }\end{array}$ \\
\hline \multirow{2}{*}{$\begin{array}{c}\text { Graphic } \\
\text { Representation }\end{array}$} & Building & 4.500 & 4.500 & 3.375 & 3.467 \\
\hline & Residence & 4.667 & 4.667 & 3.813 & 3.313 \\
\hline \multirow{2}{*}{$\begin{array}{c}\text { Humanized } \\
\text { Presentation }\end{array}$} & Building & 4.500 & 4.667 & 3.733 & 3.533 \\
\hline & Residence & 4.500 & 4.667 & 3.800 & 3.600 \\
\hline \multirow{2}{*}{ Notations } & Building & 4.167 & 4.333 & 3.467 & 3.267 \\
\hline & Residence & 4.500 & 4.667 & 3.800 & 3.400 \\
\hline \multicolumn{2}{|c|}{ Media } & 4.472 & 4.583 & 3.665 & 3.430 \\
\hline \multicolumn{2}{|c|}{ Standart Deviation (\%) } & 3.7 & 3.0 & 5.3 & 3.7 \\
\hline
\end{tabular}

The Fig. 3 shows the score evaluation by technology to demonstrate the difference between each product at different technologies. The Fig. 4 shows the Score Evaluation by Product, to show the impact of the technology above each product. All the results of table 1 were analyzed in a Pearson correlation whose results are shown at table 3 .

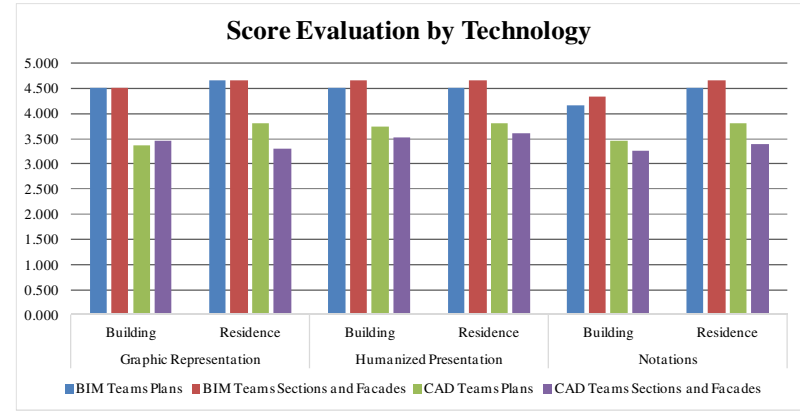

Fig. 3. Score Evaluation by Technology 
Table 3. Pearson Correlation in Data Series Analyzed

\begin{tabular}{c|c|c}
\hline \multicolumn{3}{|c}{ Pearson Correlation in Data Series } \\
Analysed \\
\hline Object & Tecnology & Pearson \\
\hline Plans & CAD & \multirow{2}{*}{0.57} \\
\cline { 2 - 2 } & BIM & \\
\hline \multirow{2}{*}{$\begin{array}{c}\text { Sections } \\
\text { and } \\
\text { Facades }\end{array}$} & CAD & \multirow{2}{*}{0.54} \\
\cline { 2 - 2 } & BIM & \\
\hline
\end{tabular}

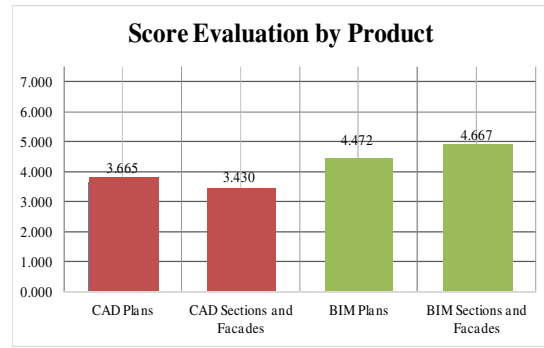

Fig. 4. Score Evaluation by Product

\section{Discussion}

The analysis of the data in Table 1 and Fig. 3 demonstrate that the development of a project with BIM tools is more efficient than CAD tools. The first tool had a score of 4.5 while the second had an average score of 3.5. This data demonstrates that, for a group of users with the same prior-knowledge, the utilization of BIM enhances the quality of the final product.

Analyzing the scenario set out in Fig. 4, it's possible to discern that, specifically for sections and elevations design, the use of BIM generates an increase of approximately $35 \%$ on the final quality of the products developed. It can be explained by the parametric software interface that allows changing the $2 \mathrm{D} / 3 \mathrm{D}$ interface, allowing the realization of more efficient work by the user.

Students have great difficulty in implementing sections and facades. The use of BIM make this process more didactic and efficient, allowing the project adjusting to solve the problems presented while the execution of sections and facades.

\section{Conclusions}

The challenges to the use of PBL tools in an undergraduate course are many. Not all students have the same level of knowledge, which significantly interferes with the quality of the projects that are developed. But the use of these tool permits the simulation of what will be developed in the working life.

In the proposed case study, the use of BIM tools demonstrated to be more efficient when compared to CAD tools. Assuming that all students involved possessed the same level of knowledge about the tools in use, the use of BIM proves to be more efficient.

Taking into account that the essences of BIM tools are integration, its use in an undergraduate course opens up a range of different exercise possibilities, allowing better simulation of what is developed in real life. In real life, the professional will deal with different professionals, and BIM tools have possibilities of collaborative engineering, 
which puts the tool in evidence for market evolution. The Data Set analyzed showed a $>0.50$ Pearson Correlation (moderate correlation) which validates the data analyzed in this case.

Acknowledgment. The authors would like to thank CAPES (Coordenação de Aperfeiçoamento de pessoal de nível Superior) and the Paulista University (UNIP) for the financial support to develop this work.

\section{References}

1. Souza, A.F., Coelho, R.T.: Tecnologia CAD/CAM - Definições e estado da arte visando auxiliar sua implantação em um ambiente fabril in XXIII Encontro Nacional de Engenharia de Produção - ENEGEP (October 24, 2003),

http://www.abepro.org.br/biblioteca/ENEGEP2003_TR0504_0920.pdf (accessed on: March 2014)

2. Migilinskas, D., Popov, V., Juocevicius, V., Ustinovichius, L.: The Benefits, Obstacles and Problems of Practical Bim Implementation. In: 11th International Conference on Modern Building Materials, Structures and Techniques, MBMST 2013, Science Verse (2013), http: //dx.doi.org/10.1016/j.proeng.2013.04.097 (acessed on: March 2014)

3. Porwal, A., Hewage, K.N.: Building Information Modeling (BIM) partnering framework for public construction projects. Automation in Construction 31, 203-214 (2014), http://dx.doi.org/10.1016/j.autcon.2012.12.004 (accessed on: March 2014)

4. Ríoz, I., Cazorla, A., Díaz-Puente, J.M., Yagüe, J.L.: Project-based learning in engineering higher education: two decades of teaching competences in real environments. Procedia Social and Behavioral Sciences 2 (2014),

http://dx.doi.org/10.1016/j.sbspro.2010.03.202 (acessed on March 2014)

5. Masson, T.J., Miranda, L.F., Munhoz, J.R., Castanheira, A.M.P.: Metodologia de Ensino: Project-Based Learning. COBENGE - XL Congresso Brasileiro de Ensino de Engenharia (2012),

http: / / www . abenge.org.br/revista / index . php/abenge/article/

download/101/81 (acessed on March, 2014) 